Ágora Rev. Cient. 2019; 06(02):e5

\title{
Evaluación del efecto cicatrizante del azúcar comercial en comparación con el ácido fusídico en piel de conejos
}

\author{
Evaluation of healing effect of commercial sugar compared to fusidic acid in rabbit skin \\ Judith Soledad Sudario Arainga ${ }^{1}$, Fidel Ernesto Acaro Chuquicaña ${ }^{1}$
}

\section{RESUMEN}

Objetivo: Evaluar el efecto cicatrizante del azúcar comercial comparado con el ácido fusídico al $2 \%$ en heridas inducidas en piel de conejo. Materiales y Métodos: Estudio cualitativo experimental, observacional in vivo analítico en conejos con lesiones de piel. Se trató las heridas con azúcar rubia (10 y $20 \mathrm{~g})$ de forma directa y también con ácido fusídico al 2\%. Mediante estudio comparativo, se evaluó la efectividad del tratamiento en las lesiones. Resultados: La sacarosa resultó efectiva para curar de las heridas y estimular la cicatrización en conejos, obteniendo resultados similares al ácido fusídico al 2\%, el tejido de granulación se observó precozmente, lo que permitió observar las fases de cicatrización con 10 días de tratamiento. Conclusiones: Se demostró el efecto farmacológico cicatrizante de la sacarosa similar al ácido fusídico al $2 \%$ de forma directa $(20 \mathrm{~g})$.

Palabras clave: azúcar, cicatrización, heridas.

\begin{abstract}
Objective: To evaluate the healing effect of commercial sugar compared to $2 \%$ fusidic acid in wounds induced in rabbit skin. Materials and Methods: Qualitative experimental, observational, in vivo analytical study in rabbits with skin lesions. Wound were treated with blond sugar (10 and $20 \mathrm{~g})$ directly applied and also with $2 \%$ fusidic acid. By comparative study, the effectiveness of the treatment in the lesions was evaluated. Results: Sucrose was effective to cure wounds and stimulate healing in rabbits, obtaining similar results to fusidic acid at $2 \%$, granulation tissue was observed early, which allowed to observe the healing phases with 10 days of treatment. Conclusions: it was demonstrated the pharmacological healing effect of sucrose similar to $2 \%$ fusidic acid directly (20 g).
\end{abstract}

Keywords: sugar, healing, wounds.

${ }^{1}$ Universidad María Auxiliadora. Escuela Profesional de Farmacia y Bioquímica. Lima - Perú.

\section{INTRODUCCIÓN}

Desde hace muchos años siempre se buscado soluciones para el tratamiento de una herida y facilitar su cicatrización que se presenta quirúrgico o traumática. Con el paso de los años se ha ido buscando soluciones que no cause una infección ya que una herida infectada lleva a una mala cicatrización del tejido epitelial. Por esta razón los profesionales de la salud han encontrado muchas maneras para tratar una herida: la sutura absorbible, las grampas o los adhesivos, pero no es suficiente porque no asegura una buena cicatrización [1].

La frecuente exposición a las agresiones del entorno hace que este órgano llamado piel sea susceptible a sufrir lesiones que comprometan su integridad, alterando el normal desarrollo de sus funciones. Uno de los factores que comprometen la continuidad de este tejido son las heridas que se presenta por cualquier agente agresor, las cuales han constituido un problema de Salud Pública que afecta a toda persona que haya sufrido una agresión física o traumática [2].

El tratamiento y cuidado de una herida para obtener una cicatrización favorable constituye un gasto importante en salud y en la comunidad. La herida por quemaduras, heridas quirúrgicas $\mathrm{y}$ traumáticas, úlceras diabéticas en miembros inferiores y heridas en la piel es un gran desafío para el profesional médico con las terapias actuales que se centran principalmente en las medidas de atención de apoyo. La cicatrización exitosa de la herida requiere una serie de pasos 
estrechamente coordinados que incluyen inflamación, proliferación, formación de tejido nuevo [3].

Diversos factores pueden producir una dehiscencia en la herida, por un lado una mala perfusión sanguínea y la presencia de elementos extraños dificultarán la cicatrización. Estos factores provocarán grandes cantidades de exudado el cual será metabolizado por las enzimas proteolíticas de los leucocitos, dando como resultado la resorción de exudado que en ausencia de necrosis celular permitirá que el tejido recupere su estructura normal; sin embargo, en acumulaciones mayores de exudado, el tejido empezará a organizarse, el tejido de granulación crecerá produciéndose la desestructuración del tejido en esa región al formarse una cicatriz [4].

El azúcar (sacarosa) ha sido usada durante muchos años para la cicatrización de herida Este tratamiento es conveniente y económico, aunque no es aséptico la sacarosa es un producto natural que por sus propiedades se considera bacteriostática, bactericida y estimulante de la cicatrización [5]. La aceleración de la cicatrización de las heridas se considera ahora como un tratamiento clínico principal y aumenta la calidad y la velocidad de la curación, lo que siempre ha sido enfatizado por los médicos. El propóleos y la miel son productos naturales de abeja en sus propiedades químicas se encuentra la sacarosa; sin embargo, en los últimos años se está utilizando esta medida con buenos resultados en él ser humano e incluso en animales, es por ello que nos vemos en la necesidad de buscar nuevas alternativas de productos naturales que no produzcan daño alguno a ser humano, como es el uso del azúcar comercial en curaciones y cicatrización de heridas [6].

El azúcar comercial (sacarosa) proviene de la caña de azúcar, su forma granulada ("azúcar comercial") y la miel ha sido utilizada por nuestros antepasados desde hace muchos años para la cicatrización de heridas en el ser humano, en la actualidad es empleada en algunos países para curar heridas infectadas y ente empezando a tener aceptación para uso veterinario, Entre las particularidades del azúcar figura la ventaja de no tener fecha de caducidad $\mathrm{y}$, por su proceso de elaboración, sale de fábrica totalmente estéril. La sacarosa posee propiedades antibacterianas, bacteriostáticas, antisépticas, desbridantes, antiedematosas, inmunológicas, estimulantes de la cicatrización y no se absorbe por vía tópica ni provoca irritación. Su aplicación en piel y mucosas genera una presión osmótica que deshidrata el citoplasma bacteriano, provocando por un lado la lisis bacteriana y por otro la incapacidad reproductora de las bacterias no lisadas de las heridas [7].

Actualmente en el Perú, también es un problema la cicatrización de una herida, desde hace muchos años, varios productos vegetales se han utilizado en el tratamiento de heridas para favorecer su cicatrización; por ejemplo, existen extractos de hierbas que promueven la coagulación de la sangre, combaten la infección y aceleran su curación. El valor medicinal de estas plantas radica en constituyentes fitoquímicos bioactivos. Estos componentes incluyen diversas familias químicas como alcaloides, aceites esenciales, flavonoides, taninos, saponinas, y compuestos fenólicos, las plantas medicinales se han utilizado para curar heridas como por ejemplo, existen plantas medicinales que interviene en la coagulación de la sangre combaten la infección y aceleran su curación, antinflamatorio y como analgésico. El azúcar posee asimismo propiedades desodorizantes ya que las bacterias usan glucosa en lugar de aminoácidos para su metabolismo, produciendo ácido láctico en lugar de amonio, aminas y compuestos azufrados el azúcar atrae macrófagos, que participan en la "limpieza de la herida", acelerando el desprendimiento de tejido desvitalizado, necrótico y/o gangrenoso, aportando una fuente de energía local y formando una capa proteica protectora en la herida. El azúcar no solo absorbe líquidos del citoplasma de las bacterias, sino de las células superficiales del lecho de la herida [8].

\section{MATERIALES Y MÉTODOS}

El estudio realizado se basa en una metodología experimental, además de ser un estudio preliminar. La muestra de estudio consideró 8 conejos procedentes del Instituto Nacional de Salud. Se formó 4 grupos cada grupo conformado por dos conejos de la siguiente manera:

- Primer grupo control: sólo se provocó la herida con un bisturí.

- Segundo grupo: 20 g de azúcar comercial diluido en $10 \mathrm{~mL}$ y directo.

- Tercer grupo: $10 \mathrm{~g}$ de azúcar comercial diluido en $5 \mathrm{~mL}$ y directo.

- Cuarto grupo: ácido fusídico al $2 \%$ capa gruesa y capa fina

\section{RESULTADOS}

Con el empleo del ácido fusídico (capa fina), se alcanzan las fases de reparación. Por otro lado, se evidencia en el décimo día que las muestras 
correspondientes a la "no adición de sustancias" y la adición de "10 gr. Azúcar diluida" no alcanzan la fase de reparación, llegando solamente a la fase de proliferación. Las muestras con adición de "20gr. Azúcar directa", "20gr. Azúcar diluida", "10gr. Azúcar directa", "10gr. Azúcar diluida", "Ácido Fusídico (capa gruesa)” y “Ácido Fusídico (capa delgada)" alcanzan la fase de reparación.

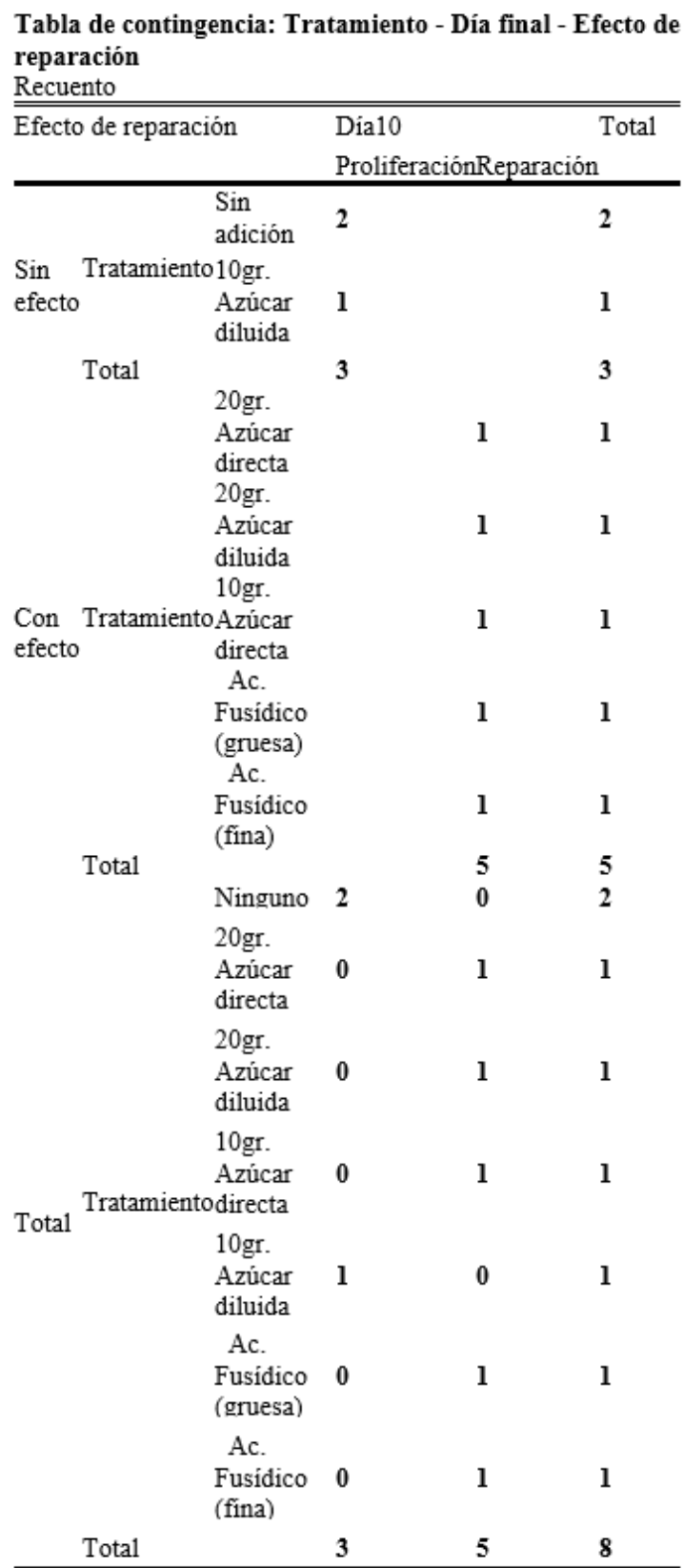

Se evidencia que las muestras que alcanzan la fase de reparación corresponden a aquellas con adición de "20gr. Azúcar directa", "20gr. Azúcar diluida", "10gr. Azúcar directa", "10gr. Azúcar diluida", "Ácido Fusídico (capa gruesa)” y “Ácido Fusídico (capa fina)".

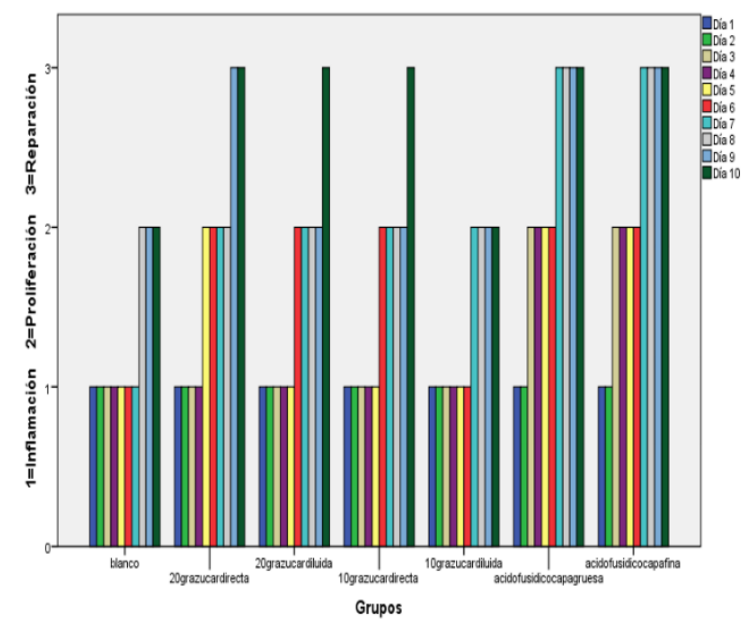

\section{DISCUSIÓN}

En la Tabla de Contingencia, se evidenciaron los resultados preliminares del efecto cicatrizante del azúcar rubia directo en base a 20 gramos, en un tratamiento de 10 días en comparación con el grupo control fue superior porque éste no recibió tratamiento. En los tratamientos de 20 gr de azúcar diluida, $10 \mathrm{~g}$ de azúcar directa y $10 \mathrm{~g}$ de azúcar diluida, no se observa cicatrización notoria, aunque el proceso del cierre de la herida fue deficiente. Afirmamos que la reversión de la herida fue mayor a los díez días de tratamiento. En cuanto al ácido fusídico al $2 \%$ capa gruesa y ácido fusídico al 2\% capa fina, en relación al azúcar rubia directo en base de 20 gramos los resultados obtenidos fue similar. Fue aceptada la hipótesis alterna estadísticamente.

\section{CONCLUSIONES}

El efecto farmacológico cicatrizante del azúcar comercial (azúcar rubia) en comparación con el ácido fusídico al $2 \%$ en piel de conejos, fue el efecto similar a la concentración del azúcar rubia de $20 \mathrm{~g}$ directo en el proceso de la cicatrización de heridas. Asimismo, el azúcar rubia $20 \mathrm{~g}$ directa en comparación con el ácido fusídico al $2 \%$, en piel de conejos, los resultados preliminares fueros similares, es decir el efecto del medicamento comercial no supera al agente del estudio desde el punto de vista estadístico. Por otro lado, el efecto cicatrizante del azúcar comercial (azúcar rubia 20 g) diluido en $10 \mathrm{~mL}$ comparación con el ácido fusídico al $2 \%$ en piel de conejo, no se evidencia resultados favorables, aunque el control positivo el efecto cicatrizante es superior. Además, el efecto cicatrizante del ácido fusídico al $2 \%$ versus el azúcar comercial (azúcar rubia 10 g) fue 
superior en piel de conejos. Finalmente, no hubo efecto cicatrizante en los tratamiento programados del azúcar comercial (azúcar rubia $20 \mathrm{~g}$ diluido) azúcar $10 \mathrm{~g}$ directo y diluido en $5 \mathrm{~mL}$ en comparación con el ácido fusídico al $2 \%$ en piel de conejos.

\section{AUTOR DE CORRESPONDENCIA}

Judith Soledad Sudario Arainga

Universidad María Auxiliadora

Av. Canto Bello No 431, Lima - Perú

Teléfono: +51-1-3891212

E-mail: judith20_83@hotmail.com

\section{REFERENCIAS BIBLIOGRÁFICAS}

1. Meza, F. Kiyomi del Pilar, M. Eficacia del adhesivo tisular para el cierre de heridas quirúrgicas. Tesis Universidad Wiener año.2017.

2. Guarín, C. Quiroga, P. Landínez NS. Proceso de cicatrización de heridas de piel, campos endógenos y su relación con las heridas crónicas. Rev. Fac. Med. 2013;(61):441-448.

3. Lin, P. Sermersheim, M. Li,H. Lee, P. Steinberg, S. Ma J. Zinc in Wound Healing Modulation. Nutrients 10(1): 1-20.

4. Vargas, A. Regeneración y cicatrización. Revista de Actualización Clínica. . 2014; (43).

5. Maritania, C. Alarcón, I. Sebazco, C. Maceira, M. Importancia de la sacarosa para la cicatrización de heridas infectadas. Revista Cubana de Medicina Militar. 2013 Marzo; 42(1): 49-55.

6. Takzaree,N. Hadjiakhondi, A. Hassanzadeh, G. Rouini, M. Manayi, A. Synergistic Effect of Honey and Propolis on Cutaneous Wound Healing in Rats. Acta Med Iran. 2016; 54(4):233-239.

7. Pintos, S. González, R., González, E. Cicatrización de injertos cutáneos en malla de espesor completo utilizando azúcar granulado versus nitrofurazona en caninos. Revista veterinaria. 2015; 26(2), 103-107.

8. Paco, K. Ponce, L. López, M. Aguilar, J. determinación del efecto cicatrizante de Piper aduncum (matico) en fibroblastos humanos. Revista Peruana de Medicina Experimental y Salud Pública. 2016; 33(3):438-47. 